\title{
Breckle, S.-W.: Walter's Vegetation of the Earth. The Ecological Systems of the Geo-Biosphere. -
} Springer-Verlag, Berlin - Heidelberg - New York 2002. 527 pp. EUR 59.95. ISBN 3-540-43315-5.

Most of the monumental work of Professor Heindrich Walter, including the two large volumes of Die Vegetation der Erde in öko-physiologischer Betrachtung, were published originally in German and remained for many years separated by a language barrier from potential users. Fortunately enough, in 1970 he published a digest from the two volumes in form of slender textbook covering zonal types of vegetation of all continents. An extraordinary success of the textbook is well documented by its seven German and four English editions, including the reviewed title. It is quite understandable, that many new insights and facts had to be included to the original text in the course of its subsequent re-editing, but the general concept remains unchanged. The reviewed book is based on translation from the $7^{\text {th }}$ German edition of Vegetation und Klimazonen, published 9 years after the death of the original author, Prof. Walter. The new edition was significantly revised, enlarged and updated by Prof. Siegmar-Walter Breckle, a close collaborator of Prof. Walter.

The whole book is divided into two sections. The first (general) section is devoted to explanation of basic ecological principles as, e.g., hierarchy of ecological systems, main features of the most important biomes and ecosystems, and approaches to their classification. Importance of individual ecological factors for ecosystem structure and functioning is also explained in several chapters within the first section. An unifying approach from the most complex (global) level to particular cases of plant-environment interactions is used in all cases. Of course, application of standardised climate diagrams, introduced by Prof. Walter, is explained in detail and their advantages for comparative ecological studies are documented in numerous examples.

The second (and more extensive) section of the book comprise descriptions of ecological conditions and vegetation types in each of the nine ecological climatic zones (designated as zonobiomes), from tropical rain forest to arctic tundra. The comprehensive characteristics of individual zonobiomes are given in an extremely clear and readable way. Numerous carefully selected original photographs, tables, maps, and schematic drawings are included. In contrary to many other textbooks on plant ecology with more or less descriptive approach, in this case the main stress is placed on explanation of causal relationships between prevailing environmental factors and the presence of specific types of biota (mainly plants). Knowledge of underlying physiological and structural traits of plant adaptations is necessary for such an approach.

The value of this textbook is further increased by addition of control questions at the end of all chapters, by a list of commonly used units of physical quantities with appropriate conversion factors, and by a glossary of foreign technical words used in ecological publications. In addition, the book has very attractive and practical design of printing. I may fully recommend it to students of biological and ecological disciplines, and to anybody who is interested in basic information on plantenvironment relationships in all continents of our planet. 